\title{
El Turismo alternativo: opción de producto turístico para el Departamento de Ñeembucú.
}

\author{
Tania Inocencia Riveros Montiel \\ Facultad de Ciencias, Tecnologías y Artes, Universidad Nacional de Pilar \\ Pilar, Paraguay \\ taniariveros2007@hotmail.com
}

\section{RESUMEN}

Este trabajo describe y analiza el Turismo Alternativo. Tal abordaje pretende orientar la planificación turística privada y/o pública, considerando al Turismo Alternativo como una opción válida para aportar al desarrollo turístico en el Departamento de Neembucú de la República del Paraguay. El objetivo de esta investigación fue identificar y evaluar los sitios con potencial para el desarrollo de productos vinculados al turismo alternativo en Neembucú, así como las principales limitantes para su implementación. Este estudio de enfoque cualitativo, alcance descriptivo, ha tomado como punto de partida la revisión bibliográfica de los postulados teóricos del Turismo Alternativo y los aspectos relacionados al mismo, el reconocimiento de los recursos y atractivos turísticos de los distritos del departamento de Neembucú se obtuvo del trabajo de campo desarrollado en el marco de la ejecución del Proyecto de investigación Potencialidad del Turismo como alternativa para el desarrollo sostenible en el departamento de Ñeembucú. Se identificaron destinos con potencial para el desarrollo del turismo alternativo. Se destaca que la implementación requerirá de una planificación participativa que involucre a la población local anfitriona, gestores públicos y/o privados, acompañados de una necesaria y perentoria inversión en infraestructura turística mínima que brinde garantías de sostenibilidad.

PALABRAS CLAVES: turismo, turismo alternativo, turismo verde, ecoturismo, producto turístico 


\title{
The alternative Tourism: option of tourist product for the Department of Ñeembucú.
}

\begin{abstract}
This work describes and analyzes Alternative Tourism. This approach aims to guide private and / or public tourism planning, considering Alternative Tourism as a valid option to contribute to tourism development in the Neembucú Department of the Republic of Paraguay. The objective of this research was to identify and evaluate the sites with potential for the development of products linked to alternative tourism in Neembucú, as well as the main limitations for its implementation. This study of qualitative approach, descriptive scope, has taken as a starting point the literature review of the theoretical postulates of Alternative Tourism and the aspects related to it, the recognition of the resources and tourist attractions of the districts of the Neembucú department was obtained from field work developed in the framework of the execution of the Tourism Potential Research project as an alternative for sustainable development in the Neembucú department. Destinations with potential for the development of alternative tourism were identified. It is emphasized that the implementation will require participatory planning that involves the local host population, public and / or private managers, accompanied by a necessary and urgent investment in minimum tourism infrastructure that provides sustainability guarantees.
\end{abstract}

KEY WORDS: tourism, Alternative tourism, Green tourism, ecotourism, tourist product

Artículo recibido: 12. feb. 2020

Aceptado para publicación: 15. mar. 2020

Correspondencia: taniariveros2007@ hotmail.com

Conflictos de Interés: Ninguna que declarar 


\section{INTRODUCCIÓN}

La Organización Mundial del Turismo (OMT) y la Organización de los Estados Americanos (OEA), (2018) señalan que el turismo como motor económico está llamada a la promoción de buenas prácticas que contribuyan con el logro de los Objetivos de Desarrollo Sostenible (ODS) del Programa de las Naciones Unidas para el Desarrollo, entre ellos la reducción de la pobreza, el desarrollo de las comunidades y la protección del medioambiente.

Parte del desarrollo socioeconómico de un destino tiene al turismo, según Moreno Melgarejo, Ignacio , y Reyes , (2018) como elemento dinamizador que tiene repercusiones en diferentes esferas del desarrollo ya sea económico, social, ambiental, cultural, entre otros.

Es una actividad ligada al movimiento de personas, quienes atraídas por deseos y necesidades y/o motivaciones se trasladan a un destino distinto al de su origen.

La Organización Mundial del Turismo (OMT), considera al turismo como un sector que "puede estimular el crecimiento económico, crear trabajo decente y oportunidades empresariales, así como ayudar a millones de personas a salir de la pobreza y mejorar sus medios de vida" (Organización Mundial del Turismo, 2016)

Por otra parte, ha quedado demostrado que la denominación propagandística de industria sin chimeneas otorgada al turismo, ha sido más que una falacia, tal como lo señala Ledhesma (2017), este sector sin una adecuada gestión "no solo puede contribuir con la degradación ambiental, sino también con el deterioro del patrimonio de toda una comunidad."

El turismo es un sector que propone una diversidad de segmentos que van generándose de manera dinámica, en concordancia con las motivaciones que hacen al desplazamiento del turista, con las ofertas que planteen los operadores residentes y/o en relación al medio físico donde se sitúa la actividad. En esta investigación nos enfocaremos en las opciones que propone el Turismo Alternativo y sus segmentos.

\section{El desarrollo sostenible}

La Comisión Mundial sobre el Medio Ambiente y el Desarrollo de las Naciones Unidas, (1987) define el desarrollo sostenible en estos términos "Está en manos de la humanidad hacer que el desarrollo sea sostenible, duradero, o sea, asegurar que satisfaga las necesidades del presente, sin comprometer la capacidad de las futuras generaciones para satisfacer las propias".

La expresión sostenible se introduce en el sector turismo en el año 1991 durante la celebración del 41 Congreso de la Asociación Internacional de Expertos Científicos del Turismo (AIEST). (Blasco, 
2005). Definiéndola como "un turismo que mantiene un equilibrio entre los intereses sociales, económicos y ecológicos [...] debe integrar las actividades económicas y recreativas con el objetivo de buscar la conservación de los valores naturales y culturales" (López, 2005: 336). (Vargas Martínez y Sánchez Valdés, 2015)

La Organización Mundial del Turismo define turismo sostenible como "El turismo que tiene plenamente en cuenta las repercusiones actuales y futuras, económicas, sociales y medioambientales para satisfacer las necesidades de los visitantes, de la industria, del entorno y de las comunidades anfitrionas"

\section{Es así que el modelo de turismo sostenible debe (Organización Mundial del Turismo, 2004):}

1) Dar un uso óptimo a los recursos medioambientales, que son un elemento fundamental del desarrollo turístico, manteniendo los procesos ecológicos esenciales y ayudando a conservar los recursos naturales y la diversidad biológica.

2) Respetar la autenticidad sociocultural de las comunidades anfitrionas, conservar sus activos culturales y arquitectónicos y sus valores tradicionales, y contribuir al entendimiento y la tolerancia intercultural.

3) Asegurar unas actividades económicas viables a largo plazo, que reporten a todos los agentes, unos beneficios socio-económicos bien distribuidos, entre los que se cuenten oportunidades de empleo estable y de obtención de ingresos y servicios sociales para las comunidades anfitrionas, y que contribuyan a la reducción de la pobreza.

Desde esa mirada la Asamblea General de las Naciones Unidas, (2015) en su parte resolutiva ha solicitado a los Estados Miembros "promover medidas a todos los niveles, en particular mediante la cooperación internacional, y a que apoyen el turismo sostenible como forma de promover y acelerar el desarrollo sostenible, especialmente la erradicación de la pobreza"

El desarrollo sostenible en el sector turístico es una necesidad y garantía de futuro. Se trata de una estrategia necesaria que permite insertar el turismo en un marco de compatibilidad con el medio ambiente, la sociedad, con el patrimonio cultural y con la economía. (Joan, 2016)

\section{Las Modalidades del Turismo}

A mediados de los 80, en Europa un grupo de ambientalistas nucleados en el movimiento por un turismo consciente y responsable otorgó la denominación de Turismo alternativo a todas aquellas ofertas de turismo, distintas a la del turismo tradicional o de masas. 
El turismo de masas recibe esta denominación por el volumen de turistas que participan en él y el alto grado de concentración espacial que caracteriza a la actividad turística en el lugar de destino, la cual puede llegar a superar, en muchos casos, la capacidad soportante de los recursos naturales o culturales allí existentes. (Miguel, 2010)

\section{Como característica en el turismo tradicional:}

"Los turistas no tienen interés en introducirse en la cultura local de la región visitada sino, bien al contrario, suelen formar ghettos en los que siguen manteniendo las costumbres de sus países de origen y se relacionan con individuos de su misma nacionalidad" (Amparo y Buhalis, 1998)

En tanto, para Ibáñez y Rodriguez, (2017) El Turismo Alternativo es una corriente de turismo que tiene como objetivo la realización de viajes donde el turista participa en actividades recreativas de contacto con la naturaleza y las expresiones culturales de comunidades rurales, indígenas y urbanas, respetando los patrimonios natural, cultural e histórico del lugar que visitan. Presupone que los organizadores están conscientes de los valores naturales, sociales y comunitarios, y que los turistas desean interactuar con la población local.

"El turismo alternativo presenta una opción para el desarrollo de actividades recreativas a pequeña escala en comunidades o lugares en los que es posible llevar adelante un control más estricto de los impactos negativos de la actividad" (NARVAEZ, 2014)

Así también, Miguel (2006) señala como característica del turismo alternativo, que este puede ser manejado por empresas pequeñas y medianas que incorporan en su operación personal reclutado en las comunidades locales, lo cual, además de la participación activa de éstos en la actividad, permite la práctica de un desarrollo sostenible, y la garantía de protección y seguridad de los visitantes en los espacios en los cuales tiene lugar la actividad turística.

Si bien existen diversas definiciones y conceptos respecto al turismo alternativo, para los fines de esta investigación lo definiremos, como aquella actividad no masiva, que busca un equilibrio entre todos los actores involucrados en la actividad turística, siendo respetuoso con los recursos naturales y socioculturales del destino donde se desarrolla, siendo unas de sus características el contacto activo con la naturaleza y la población receptora.

Si bien no existe una clasificación general, en la Tabla 1 se exponen los segmentos asociados al Turismo Alternativo con una serie de actividades que bien podrían desarrollarse dentro de cada clasificación identificados por SECTUR y SENATUR respectivamente. 


\begin{tabular}{|c|c|}
\hline SEGMENTOS & ACTIVIDADES \\
\hline $\begin{array}{l}\text { ECOTURISMO } \\
\text { "Los viajes que tienen como fin el realizar } \\
\text { actividades recreativas de apreciación y } \\
\text { conocimiento de la naturaleza a través del contacto } \\
\text { con la misma." (SECTUR, 2002) }\end{array}$ & $\begin{array}{l}\text { - } \text { Talleres de educación ambiental } \\
\text { - } \text { Senderismo interpretativo (Trekking) } \\
\text { - } \text { Safari Fotográfico } \\
\text { - } \text { Obserate de flora y fauna } \\
\text { - Observación de flora y fauna autóctona } \\
\text { - } \text { Observación de atractivos naturales } \\
\text { - } \text { Observación Sideral - Astro turismo }\end{array}$ \\
\hline $\begin{array}{l}\text { TURISMO DE AVENTURA } \\
\text { "Los viajes que tienen como fin el realizar } \\
\text { actividades recreativas deportivas, asociadas a } \\
\text { desafíos impuestos por la naturaleza." (SECTUR, } \\
2002 \text { ) }\end{array}$ & $\begin{array}{l}\text { - Rappel } \\
\text { - Tirolesa } \\
\text { - } \text { Cabalgata } \\
\text { - Escalada } \\
\text { - Ciclismo } \\
\text { - Canotaje } \\
\text { - Kayaquismo } \\
\text { - } \text { Pesca Deportiva } \\
\text { - } \text { Caminata } \\
\text { - } \text { Areo en Lancha } \\
\text { - } \text { Buceo } \\
\text { - Paracaidismo }\end{array}$ \\
\hline $\begin{array}{l}\text { TURISMO RURAL } \\
\text { "Los viajes que tienen como fin el realizar } \\
\text { actividades de convivencia e interacción con una } \\
\text { comunidad rural, en todas aquellas expresiones } \\
\text { sociales culturales y productivas cotidianas de la } \\
\text { misma." SECTUR, (2002) } \\
\text { "Conjunto de actividades que se desarrollan en dicho } \\
\text { entorno, excediendo el mero alojamiento y que } \\
\text { pueden constituirse para los habitantes del medio en } \\
\text { una fuente de ingresos complementarios a los } \\
\text { tradicionalmente dependientes del sector primario } \\
\text { (...)" (SENATUR, 2018) }\end{array}$ & $\begin{array}{l}\text { - } \text { Talleres artesanales } \\
\text { - } \text { Etnoturismo } \\
\text { - } \text { Agroturismo (observación o participación } \\
\text { - } \text { Paseos a caballo, carro, botes o pesca. } \\
\text { - Preparación y uso de medina tradicional } \\
\text { - } \text { Talleres y disfrute gastronómico } \\
\text { - } \text { Fotografía rural } \\
\text { - } \text { Aprendizaje de dialectos } \\
\text { - } \quad \text { Vivencias místicas (conocer y participar } \\
\quad \text { en la riqueza de las creencias, leyendas y } \\
\text { - } \text { rituales divinos de un pueblo) } \\
\text { - } \text { Posadas Turísticas }\end{array}$ \\
\hline
\end{tabular}




\begin{tabular}{|c|c|}
\hline $\begin{array}{l}\text { TURISMO CULTURAL (existe una estrecha } \\
\text { relación con el TURISMO RURAL) } \\
\text { "Se define como aquel viaje turístico motivado por } \\
\text { conocer, comprender y disfrutar el conjunto de } \\
\text { rasgos y elementos distintivos, espirituales y } \\
\text { materiales, intelectuales y afectivos que caracterizan } \\
\text { a una sociedad o grupo social de un destino } \\
\text { específico." (SECTUR, 2015) }\end{array}$ & $\begin{array}{l}\text { - } \text { Viaje de estudios. } \\
\text { - Representaciones artísticas, festivales } \\
\text { u otros eventos culturales. } \\
\text { - Visitas a lugares y monumentos } \\
\text { históricos (museos, sitios de batallas } \\
\text { etc) } \\
\text { - Folklore, arte o peregrinación. } \\
\text { - Expresiones de la cultura popular: } \\
\text { tradiciones, gastronomía, fiestas, } \\
\text { celebraciones. }\end{array}$ \\
\hline
\end{tabular}

Fuente: Elaboración propia, con información de SECTUR, (2002), SENATUR, (2018) e báñez y Rodriguez, (2017)

\section{Elementos del Sistema Turístico}

En el sistema turístico convergen una serie de elementos que dinamizan la oferta y demanda turística respectivamente.

A partir de existencia del recurso turístico (la materia prima) surge el atractivo turístico (son RT que disponen de las condiciones para ser visitado y/o disfrutado por el visitante), siendo este el elemento que fomenta o motiva la creación de Productos Turísticos, es decir el conjunto de bienes y servicios que son ofertados para satisfacer la experiencia del visitante (incluyen recursos, atractivos, servicios y actividades turísticas, etc.)

$\mathrm{Al}$ igual que el atractivo, el producto turístico requiere de una Planta Turística que brinde las condiciones necesarias para la puesta en funcionamiento y que garantice la estadía del visitante en el sitio, SEGITTUR define a la Planta Turística como "el conjunto de instalaciones, equipos, empresas y personas que prestan servicio al turismo y fueron creados para este fin".

\section{Ilustración 1:Elementos del Sistema Turístico}

Fuente: Elaboración propia

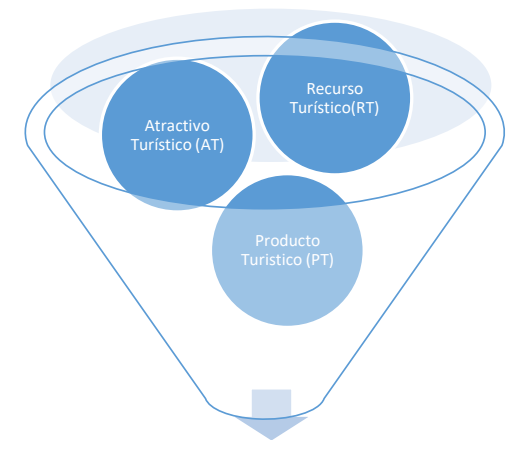

Planta Turística (PLT) 


\section{Gestión del Turismo en Paraguay}

En Paraguay, la Secretaría Nacional de Turismo (SENATUR) es el organismo rector para la regulación y desarrollo del sector turismo, creada el 30 de diciembre del año 1998, por ley $\mathrm{N}^{\circ}$ 1.388/98, con rango ministerial, dependiente de la Presidencia de la República.

Anteriormente, la actividad estaba a cargo de la Dirección Nacional de Turismo dependiente del Ministerio de Obras Públicas y Comunicaciones conforme a la Ley 152/ 1969.

El Plan Nacional de Desarrollo 2030 de la República del Paraguay, en su eje inserción de Paraguay en el mundo considera al turismo como "un sector sustancial que genera recursos importantes y envía señales positivas o negativas al exterior del país, por lo que la articulación de redes de provisión de servicios relacionados al sector constituye un objetivo importante en el posicionamiento del país.” (Secretaría Técnica de Planificación, 2014)

En relación a la gestión del Turismo Alternativo en el Paraguay, el marco normativo del sector señala "La SENATUR dará prioridad al producto turístico nacional y al desarrollo complementario del turismo alternativo, en sus diversas modalidades, en función a la demanda del mercado" (Ley 2.828 Del Turismo, 2005, art 20).

\section{MATERIALES Y MÉTODOS}

Este estudio de enfoque cualitativo, alcance descriptivo, de diseño no experimental y corte trasversal, es posible realizar a partir de la revisión bibliográfica de los postulados teóricos del Turismo Alternativo y los aspectos relacionados al mismo realizados por ( Ibáñez \& Rodriguez, 2017), (SECTUR , 2002) y (SENATUR , 2018)

Conforme adelantamos en la introducción, se pretende identificar los sitios con potencial para el desarrollo de productos vinculados al turismo alternativo en Neembucú, así como las principales limitantes para su implementación, a partir de los datos obtenidos en la investigación denominada Potencialidad del Turismo como alternativa para el desarrollo sostenible en el departamento de Ñeembucú, realizada por investigadores de la Universidad Nacional de Pilar, realizado en los 16 distritos del departamento de Ñeembucú en el mes de octubre del 2018, aplicándose como estrategia la observación y la entrevista a profundidad a informantes claves.

Los informantes están conformados por pobladores arraigados, docentes, estudiantes, emprendedores, administradores de museos públicos y privados, autoridades municipales, prestadores de servicios turísticos.

Los recursos/atractivos seleccionados son aquellos que guardan relación con la clasificación de turismo alternativo realizada por SECTUR y SENATUR respectivamente. 


\section{RESULTADOS}

En el marco de la ejecución de la investigación Potencialidad del Turismo como alternativa para el desarrollo sostenible en el departamento de Neembucú y tras el proceso de sistematización, codificación cualitativa, y categorización en unidades interpretativas; se procedió a la determinación de un Diagnóstico del Potencial Turístico del lugar, conforme a ello, se identificaron los sitios con potencial para el desarrollo del turismo alternativo.

Tabla 2: Atractivos y Segmentos Potenciales para el Turismo Alternativo

\begin{tabular}{|c|c|c|c|}
\hline Distrito & Atractivos con Potencialidad & Segmento & Observación \\
\hline Villa Oliva & $\begin{array}{l}\text { Los Pobladores de la ciudad se dedi- } \\
\text { can en su mayoría, a la pesca, agri- } \\
\text { cultura y ganadería. } \\
\text { La existencia del ciervo de los panta- } \\
\text { nos y la Reserva Natural del lago } \\
\text { Ypoá. } \\
\text { Oliva Rice (complejo agrícola-indus- } \\
\text { trial de arroz) ubicada en la compañía } \\
\text { Zanjita, en donde las plantaciones de } \\
\text { arroz son trabajadas por lugareños. }\end{array}$ & $\begin{array}{l}\text { Turismo Rural } \\
\text { Ecoturismo }\end{array}$ & $\begin{array}{l}\text { Escasa cartelería de } \\
\text { orientación turística. } \\
\text { Planta turística limi- } \\
\text { tada. } \\
\text { Dificultad para el ac- } \\
\text { ceso a la zona de la } \\
\text { Reserva del Lago } \\
\text { Ypoá. }\end{array}$ \\
\hline Alberdi & $\begin{array}{l}\text { Festival del Karanday } \\
\text { Los Esteros del Ypoá } \\
\text { Poseen gran riqueza ecológica y be- } \\
\text { lleza. Su ecosistema es rico en diver- } \\
\text { sidad de fauna y flora. }\end{array}$ & $\begin{array}{l}\text { Turismo Cul- } \\
\text { tural } \\
\text { Ecoturismo }\end{array}$ & $\begin{array}{l}\text { Escasa cartelería de } \\
\text { orientación turística. } \\
\text { Dificultad para el ac- } \\
\text { ceso a la zona de la } \\
\text { Reserva del Lago } \\
\text { Ypoá. } \\
\text { Planta turística limi- } \\
\text { tada. }\end{array}$ \\
\hline Villa Franca & $\begin{array}{l}\text { Actividades acuáticas y pesca depor- } \\
\text { tiva. } \\
\text { Se prestan servicios de alquiler de } \\
\text { kayaks. }\end{array}$ & $\begin{array}{l}\text { Ecoturismo } \\
\text { Turismo de } \\
\text { Aventura }\end{array}$ & $\begin{array}{l}\text { Posee atractivos natu- } \\
\text { rales, pero no dispone } \\
\text { de infraestructura ni } \\
\text { plan de desarrollo tu- } \\
\text { rístico. } \\
\text { Los sitios poseen gran } \\
\text { belleza natural, paisa- } \\
\text { jística y faunística, } \\
\text { Planta turística limi- } \\
\text { tada. }\end{array}$ \\
\hline $\begin{array}{l}\text { San Juan Bau- } \\
\text { tista }\end{array}$ & $\begin{array}{l}\text { Posee lagunas y arroyos: Laguna } \\
\text { Maka, Arroyo Yacaré y Arroyo Pa- } \\
\text { sito. (Son aptas para el avistaje de } \\
\text { avifauna) } \\
\text { Dispone de Hospedajes }\end{array}$ & Ecoturismo & $\begin{array}{l}\text { Falta de vías adecua- } \\
\text { das de comunicación. } \\
\text { Falta de señalización } \\
\text { en los caminos inter- } \\
\text { nos del Distrito. }\end{array}$ \\
\hline
\end{tabular}




\begin{tabular}{|c|c|c|c|}
\hline & & & $\begin{array}{l}\text { Planta turística limi- } \\
\text { tada. }\end{array}$ \\
\hline Tacuaras & $\begin{array}{l}\text { El distrito está regado por ríos y arro- } \\
\text { yos; tales como: el Río Paraguay, Río } \\
\text { Tebicuary, Arroyo Yacaré. } \\
\text { Festival internacional de la Corvina y } \\
\text { el Canto, organización privada por } \\
\text { propietarios de la Posada Tebicuary. }\end{array}$ & $\begin{array}{l}\text { Turismo Rural } \\
\text { Turismo Cul- } \\
\text { tural }\end{array}$ & $\begin{array}{l}\text { En los caminos inter- } \\
\text { nos del Distrito de Ta- } \\
\text { cuaras es nula la carte- } \\
\text { lería de orientación tu- } \\
\text { rística. } \\
\text { Planta turística limi- } \\
\text { tada. }\end{array}$ \\
\hline Guazucuá & $\begin{array}{l}\text { Edificio de } 1849 \text { - Iglesia Pura y } \\
\text { Limpia Concepción. (Construida du- } \\
\text { rante el gobierno de Carlos Antonio } \\
\text { López.) } \\
\text { Guazucuá está rodeada de lagunas y } \\
\text { esterales. Los sitios son aptos para el } \\
\text { avistaje de aves y pesca en cachiveo. } \\
\text { Arroyo Isyry, camino a Potrero Ibi- } \\
\text { ray. Arroyo Las hermanas }\end{array}$ & $\begin{array}{l}\text { Ecoturismo } \\
\text { Turismo Cul- } \\
\text { tural }\end{array}$ & $\begin{array}{l}\text { La cartelería de orien- } \\
\text { tación turística no es } \\
\text { suficiente. } \\
\text { Planta turística limi- } \\
\text { tada. }\end{array}$ \\
\hline Cerrito & $\begin{array}{l}\text { Posadas Turísticas } \\
\text { Lago Sirena } \\
\text { Festival del Lago Sirena } \\
\text { Fiesta playera Hawái en Cerrito } \\
\text { Dunas de Cerrito } \\
\text { Cerámica indígena y arqueología } \\
\text { Mirador Ita Punta } \\
\text { Islas: Isla Pombero, Martín García, } \\
\text { Isla Boca, Isla Paloma. } \\
\text { La pesca } \\
\text { Regado por el Rio Paraná }\end{array}$ & $\begin{array}{l}\text { Ecoturismo } \\
\text { Turismo Rural } \\
\text { Turismo de } \\
\text { Aventura } \\
\text { Turismo Cul- } \\
\text { tural }\end{array}$ & $\begin{array}{l}\text { Insuficiente cartelería } \\
\text { para la orientación tu- } \\
\text { rística. } \\
\text { Las vías de comunica- } \\
\text { ción no son de todo } \\
\text { tiempo. } \\
\text { Planta turística limi- } \\
\text { tada. } \\
\text { Es necesario señalizar } \\
\text { los sitios de interés y } \\
\text { estimular la oferta de } \\
\text { servicios } \\
\text { turísticos como restau- } \\
\text { rantes y bares. }\end{array}$ \\
\hline Laureles & $\begin{array}{l}\text { Edificio - Iglesia de } 1791 \text { y anfiteatro } \\
\text { al aire libre (Virgen del Rosario) } \\
\text { Fiesta de la tradición laureleña } \\
\text { Fiesta de la tradición Estecheña } \\
\text { Arroyo Piraguasú } \\
\text { Laguna Tanimbú. En la zona se pue- } \\
\text { den realizar safaris y paseos. }\end{array}$ & $\begin{array}{l}\text { Ecoturismo } \\
\text { Turismo Cul- } \\
\text { tural }\end{array}$ & $\begin{array}{l}\text { Insuficiente cartelería } \\
\text { para la orientación tu- } \\
\text { rística } \\
\text { Planta turística limi- } \\
\text { tada. }\end{array}$ \\
\hline Villalbín & $\begin{array}{l}\text { Compañía Tte. Sánchez. - Artesanía: } \\
\text { finos trabajos a base de la Planta del } \\
\text { Jata’i (sombrero, pantallas, camine- } \\
\text { ros, individuales, billeteras) } \\
\text { Dunas el denominado Indio rapé } \\
\text { Vestigios indígenas }\end{array}$ & $\begin{array}{l}\text { Eco turismo } \\
\text { Turismo Cul- } \\
\text { tural }\end{array}$ & $\begin{array}{l}\text { Nula cartelería para la } \\
\text { orientación turística. } \\
\text { Planta turística limi- } \\
\text { tada. }\end{array}$ \\
\hline
\end{tabular}




\begin{tabular}{|c|c|c|c|}
\hline & $\begin{array}{l}\text { La existencia de esteros que poseen } \\
\text { una diversidad faunística conformada } \\
\text { por carpinchos, yacarés, nutrias, cha- } \\
\text { jás. }\end{array}$ & & \\
\hline Desmochados & $\begin{array}{l}\text { Posee uno de los mejores espacios } \\
\text { polideportivos de la región que po- } \\
\text { dría ser optimizado para actividades } \\
\text { deportivas y eventos culturales. }\end{array}$ & $\begin{array}{l}\text { Turismo Cul- } \\
\text { tural }\end{array}$ & $\begin{array}{l}\text { Insuficiente cartelería } \\
\text { para la orientación tu- } \\
\text { rística. } \\
\text { Planta turística limi- } \\
\text { tada. }\end{array}$ \\
\hline $\begin{array}{l}\text { Mayor Martí- } \\
\text { nez }\end{array}$ & $\begin{array}{l}\text { Fiesta Patronal de Mayor José de Je- } \\
\text { sús Martínez } \\
\text { Laguna Falcón: ecosistema rico en } \\
\text { fauna y flora, esterales repletos de } \\
\text { aves } \\
\text { Itá Corá: Zona concurrida por los } \\
\text { apasionados a la pesca por sus costas } \\
\text { con el Río Paraná. }\end{array}$ & $\begin{array}{l}\text { Ecoturismo } \\
\text { Turismo Rural } \\
\text { Turismo de } \\
\text { Aventura }\end{array}$ & $\begin{array}{l}\text { Escasa la cartelería } \\
\text { para la orientación tu- } \\
\text { rística } \\
\text { Posee Posadas, hoteles } \\
\text { y comedores con } \\
\text { buena infraestructura. } \\
\text { Limitada Planta Turís- } \\
\text { tica. }\end{array}$ \\
\hline Isla Umbú & $\begin{array}{l}\text { Laguna Capilla } \\
\text { Fiesta Patronal de Isla Umbú "San } \\
\text { Atanasio" } \\
\text { Museo coronel Pedro Hermosa } \\
\text { Plaza central y templo de la época de } \\
\text { Carlos Antonio López. } \\
\text { Fiesta hípica Rincón Paraíso (octubre }\end{array}$ & $\begin{array}{l}\text { Turismo Cul- } \\
\text { tural } \\
\text { Eco turismo } \\
\text { Turismo Rural }\end{array}$ & $\begin{array}{l}\text { Escasa cartelería para } \\
\text { la orientación turística. } \\
\text { Sin coordinación pre- } \\
\text { via no es posible acce- } \\
\text { der apreciar los atracti- } \\
\text { vos tales como: la } \\
\text { iglesia y el museo } \\
\text { Camino de todo } \\
\text { tiempo no así para lle- } \\
\text { gar a sus compañías. } \\
\text { Planta turística limi- } \\
\text { tada. }\end{array}$ \\
\hline General Díaz & $\begin{array}{l}\text { Vestigios de la Guerra de la Triple } \\
\text { Alianza } \\
\text { Producción de miel en General Díaz } \\
\text { Artesanía en talabartería en General } \\
\text { Díaz } \\
\text { Fiesta Patronal de General Díaz } \\
\text { Fiesta de la fundación de General } \\
\text { Díaz } \\
\text { Festival Nacional Jatái } \\
\text { Playa Potrerito - Río Paranamí } \\
\text { Puerto Itá (punto escogido por pesca- } \\
\text { dores) }\end{array}$ & $\begin{array}{l}\text { Ecoturismo } \\
\text { Turismo Cul- } \\
\text { tural } \\
\text { Turismo Rural }\end{array}$ & $\begin{array}{l}\text { Nula cartelería para la } \\
\text { orientación turística. } \\
\text { Los caminos internos } \\
\text { presentan muchas difi- } \\
\text { cultades de tránsito en } \\
\text { los días de lluvia. } \\
\text { Planta turística limi- } \\
\text { tada. }\end{array}$ \\
\hline Paso de Patria & $\begin{array}{l}\text { Fiesta Patronal de Paso de Patria } \\
\text { Museo privado San Francisco Solano } \\
\text { Museo ex Cuartel General de López }\end{array}$ & $\begin{array}{l}\text { Ecoturismo } \\
\text { Turismo Cul- } \\
\text { tural }\end{array}$ & $\begin{array}{l}\text { La dificultad para el } \\
\text { acceso a las opciones } \\
\text { turísticas de Paso de } \\
\text { Patria es el estado de }\end{array}$ \\
\hline
\end{tabular}




\begin{tabular}{|c|c|c|c|}
\hline & $\begin{array}{l}\text { Itapirú (confluencia del Rio Paraná y } \\
\text { Paraguay) } \\
\text { Posada Turística } \\
\text { Zonas de guerra: Estero Bellaco, Tu- } \\
\text { yutí, Boquerón del Sauce, Jataity } \\
\text { Corá. }\end{array}$ & $\begin{array}{l}\text { Turismo de } \\
\text { Aventura }\end{array}$ & $\begin{array}{l}\text { conservación de los } \\
\text { caminos } \\
\text { Nula existencia de car- } \\
\text { telería. } \\
\text { Planta turística limi- } \\
\text { tada. }\end{array}$ \\
\hline Humaitá & $\begin{array}{l}\text { Costanera de Humaitá } \\
\text { Museo ex Cuartel del Mariscal López } \\
\text { Museos privados } \\
\text { Ruinas de San Carlos Borromeo } \\
\text { Fiesta Patronal de Humaitá } \\
\text { Trincheras de Curupayty } \\
\text { Zonas de guerra: Batería Londres, Itá } \\
\text { Punta, Cuartel Tuyucué } \\
\text { Posadas Turísticas } \\
\text { Estofado a la novia }\end{array}$ & $\begin{array}{l}\text { Turismo Cul- } \\
\text { tural } \\
\text { Turismo Rural }\end{array}$ & $\begin{array}{l}\text { La cartelería de los si- } \\
\text { tios históricos está } \\
\text { muy dañada o en ma- } \\
\text { las condiciones de } \\
\text { conservación. } \\
\text { Reúne excelentes si- } \\
\text { tios turísticos históri- } \\
\text { cos. } \\
\text { Necesita mejorar los } \\
\text { accesos y la señaliza- } \\
\text { ción turística. } \\
\text { Si bien posee cierta } \\
\text { cantidad de Posadas, } \\
\text { hoteles y comedores, } \\
\text { aún es limitada la } \\
\text { Planta Turística. }\end{array}$ \\
\hline Pilar & $\begin{array}{l}\text { Arquitectura colonial del siglo XIX } \\
\text { con marcada influencia italiana. } \\
\text { Museo histórico Cabildo } \\
\text { Museo Paolo Federico Alberzoni } \\
\text { La Basílica Nuestra Señora del Pilar } \\
\text { Paseos en Kayak sobre el arroyo } \\
\text { Neembucú } \\
\text { Fiesta Hawaiana } \\
\text { Torneo de Pesca Internacional Se- } \\
\text { mana Santa, organizado por el Club } \\
\text { Deportivo Pilarense } \\
\text { Fiesta Patronal y Fundacional de Pi- } \\
\text { lar } \\
\text { Posadas Turísticas. }\end{array}$ & $\begin{array}{l}\text { Ecoturismo } \\
\text { Turismo Cul- } \\
\text { tural }\end{array}$ & $\begin{array}{l}\text { Dispone de una Planta } \\
\text { Turística más desarro- } \\
\text { llada. } \\
\text { Tiene potencial para } \\
\text { desarrollar circuitos y } \\
\text { propuestas temáticas } \\
\text { vinculados con la iden- } \\
\text { tidad, el patrimonio ar- } \\
\text { quitectónico y las per- } \\
\text { sonalidades oriundas } \\
\text { de la ciudad que tuvie- } \\
\text { ron destacadas trayec- } \\
\text { torias. }\end{array}$ \\
\hline
\end{tabular}

Fuente: Elaboración propia en base al trabajo de campo realizado en el mes de octubre del 2018 en el marco de la ejecución del Proyecto de investigación Potencialidad del Turismo como alternativa para el desarrollo sostenible en el departamento de Ñeembucú.

\section{DISCUSIÓN}

Conforme a las clasificaciones realizadas en cada uno de los distritos del Departamento de Ñeembucú, basadas en las características de los recursos y atractivos identificados, podrían desarrollarse actividades de turismo alternativo, dada la existencia de recursos naturales, históricos y culturales con un alto potencial para este producto. 
Sin embargo, la implementación de segmentos y/o productos turísticos requieren de una puesta en valor en la infraestructura mínima requerida para atender a los visitantes, tal es el caso de garantizar las vías de acceso de todo tiempo, esto sería primordial para el inicio de cualquier proyecto de inversión turística, otro aspecto perentorio es el aseguramiento de la gestión de calidad en los servicios de alojamiento y alimentación.

Cerrito es el destino que cuenta con mayor variedad de recursos turísticos (naturales, históricos y culturales) para el turismo alternativo. No obstante, requiere de una importante intervención en los puntos señalados en el párrafo precedente.

Exceptuando la capital del Departamento, ciudad de Pilar, se observa una limitada Planta Turística tanto en cantidad como en calidad, así también una carencia en señalizaciones, dejando en descubierto una carente planificación integral en asuntos de desarrollo.

Concretar una sinergia entre el Gobierno (gestión gubernamental), empresa privada (inversión) y universidad (ámbito académico), pueden ayudar a delinear propuestas de proyectos de turismo alternativo, esto sin perder de vista la necesidad de lograr el empoderamiento de la comunidad anfitriona.

Siendo consecuentes con la gestión del desarrollo sostenible, la consolidación de esta apropiación es necesaria de tal forma a garantizar la implementación y permanencia de productos turísticos en el tiempo, que permitan satisfacer las necesidades presentes sin comprometer la existencia de las futuras generaciones.

Cabe recordar que el ejercicio del turismo alternativo requiere de la participación activa no sólo del visitante sino también de la población local con el destino donde se desarrolla la actividad, siendo respetuosos con los recursos naturales y socioculturales.

Finalmente, señalar que el turismo alternativo es una opción de desarrollo, el cual puede constituirse en una actividad económica que contribuya de manera principal o complementaria con los ingresos económicos de la población local.

\section{REFERENCIAS}

Ibáñez, R., \& Rodriguez, I. (01 de Diciembre de 2017). Tipologías y antecedentes de la actividad turística: turismo tradicional y turismo alternativo. Obtenido de agua.org.mx: https://agua.org.mx/biblioteca/tipologias-antecedentes-la-actividad-turistica-turismo-tradicional-turismo-alternativo/ 
Organización Mundial del Turismo (OMT) y La Organización de los Estados Americanos (OEA). (2018). www.e-unwto.org. Obtenido de El turismo y los Objetivos de Desarrollo Sostenible Buenas prácticas en las Américas : https://www.eunwto.org/doi/pdf/10.18111/9789284419937

Amparo, S., \& Buhalis, D. (1998). Introducción al Turismo. Madrid: Organización Mundial del Turismo.

Asamblea General de las Naciones Unidas. (2015). A/Resolución 70/193. Nueva York.

Blasco, M. (2005). Introducción al Concepto del Turismo Sostenible. Obtenido de https://www.aragon.es/: $\quad$ https://www.aragon.es/documents/20127/674325/INTRODUCCION2019.06.12.11.39.00.pdf/ede0fddd-740e-bbf1-60f0-c3a8288d167f

Castro Ayala, H. (2009). Turismo cultural y consumo cultural en viajes turísticos. Economía y Desarrollo, 154-185.

Cumbre Mundial de Desarrollo Sostenible. (26 y 27 de noviembre de 2015). http://cartamundialdeturismosostenible2015.com/. Obtenido de http://cartamundialdeturismosostenible2015.com/: http://cartamundialdeturismosostenible2015.com/wp-content/uploads/2016/05/Carta-Mundial-de-Turismo-Sostenible-20.pdf

Historia del Turismo Sostenible. (s.f.). Obtenido de Turismo Sostenible: https://sostenibilidadturistica.wordpress.com/historia-ts/

Joan, N. (2016). La visión territorial y sostenible del desarrollo local : una perspectiva multidisciplinar. Brasilia: Universidade de Valencia.

Ledhesma, M. (2017). Mitomanías del turismo. Ciudad Autónoma de Buenos Aires: Andrea Barrientos.

Ley 2.828 Del Turismo. (06 de diciembre de 2005). Asunción: Presidencia de la República del Paraguay .

Miguel, A. (2006). Conceptualización, Origen y Evolución del Turismo . México: Trillas .

Miguel, A. (18 de julio de 2010). Conceptos, tipos y modalidades de turismo III. Turismo de masa. Obtenido de http://www.portaldeamerica.com:http://www.portaldeamerica.com/index.php/columnistas/miguel-angel-acerenza/item/1952-conceptos-tipos-y-modalidades-deturismo-iii-turismo-de-masa 
Moreno Melgarejo, A., Ignacio , S., \& Reyes , Á. (diciembre de 2018). La Planificación y la Gestión como herramientas de desarrollo de los destino turísticos. Obtenido de www.eumed.net: https://www.eumed.net/rev/turydes/25/gestion-destinos.html

NARVAEZ, E. L. (2014). El turismo alternativo: una opción para el desarrollo local. Revista de Ciencias Sociales y Humanas del Instituto de Investigaciones Socio-Económicas, 9-18.

Organización Mundial del Turismo. (2004). Desarrollo Sostenible del Turismo. Obtenido de unwto: https://sdt.unwto.org/es/content/definicion

Organización Mundial del Turismo. (13 de septiembre de 2005). Declaración "El turismo al servicio de los objetivos de Desarrollo del Milenio". Obtenido de unwto: http://cf.cdn.unwto.org/sites/all/files/docpdf/declaracionny-esp.pdf

Organización Mundial del Turismo. (2013). Notas metodológicas de la base de datos de estadística de turismo. Madrid: Organización Mundial del Turismo.

Organización Mundial del Turismo. (2016). Organización Mundial del Turismo. Obtenido de Año Internacional del Turismo para el Desarrollo Sostenible. Guia para celebrarlo juntos: http://cf.cdn.unwto.org/sites/all/files/intyear/unwto-brochure-IY2017.pdf

Secretaría Técnica de Planificación. (2014). Plan Nacional de Desarrollo. Obtenido de http://www.stp.gov.py:http://www.stp.gov.py/pnd/wp-ontent/uploads/2014/12/pnd2030.pdf

SECTUR . (2002). TURISMO ALTERNATIVO "Una nueva forma de hacer turismo. Obtenido decedocvirtual.sectur.gob.mx:https://cedocvirtual.sectur.gob.mx/janium/Documentos/006145.pdf

SECTUR. (14 de mayo de 2015). Turismo Cultural . Obtenido de www.sectur.gob.mx: http://www.sectur.gob.mx/hashtag/2015/05/14/turismo-cultural/

SEGITTUR. (s.f.). Industria del turismo. Obtenido de https://www.segittur.es: https://www.segittur.es/opencms/export/sites/segitur/.content/galerias/descargas/proyectos/Industria-del-turismo.pdf

SENATUR . (2018). Plan Maestro de Desarrollo Sostenible del Sector Turístico del Paraguay 2019 - 2026. Asunción, Paraguay.

Vargas Martínez, E. E., \& Sánchez Valdés, A. (2015). Turismo sustentable. Un acercamiento a su oferta. Redalyc, 347-354. 